\title{
Fractionated Stereotactic Radiosurgery Alone for the Treatment of a Papillary Craniopharygioma
}

\author{
Tyler J. Kenning, MD \\ Thomas Jefferson University \\ James J. Evans, MD \\ Thomas Jefferson University
}

Follow this and additional works at: https://jdc.jefferson.edu/jhnj

Part of the Neurology Commons

Let us know how access to this document benefits you

\section{Recommended Citation}

Kenning, MD, Tyler J. and Evans, MD, James J. (2012) "Fractionated Stereotactic Radiosurgery Alone for the Treatment of a Papillary Craniopharygioma," JHN Journal: Vol. $7:$ Iss. 1 , Article 1.

DOI: https://doi.org/10.29046/JHNJ.007.1.005

Available at: https://jdc.jefferson.edu/jhnj/vol7/iss1/1

This Article is brought to you for free and open access by the Jefferson Digital Commons. The Jefferson Digital Commons is a service of Thomas Jefferson University's Center for Teaching and Learning (CTL). The Commons is a showcase for Jefferson books and journals, peer-reviewed scholarly publications, unique historical collections from the University archives, and teaching tools. The Jefferson Digital Commons allows researchers and interested readers anywhere in the world to learn about and keep up to date with Jefferson scholarship. This article has been accepted for inclusion in JHN Journal by an authorized administrator of the Jefferson Digital Commons. For more information, please contact: JeffersonDigitalCommons@jefferson.edu. 
Fractionated Stereotactic Radiosurgery Alone for the Treatment of a Papillary Craniopharygioma

Tyler J. Kenning, MD; James J. Evans, MD

Neurosurgery Department, Thomas Jefferson University, Philadelphia, Pennsylvania

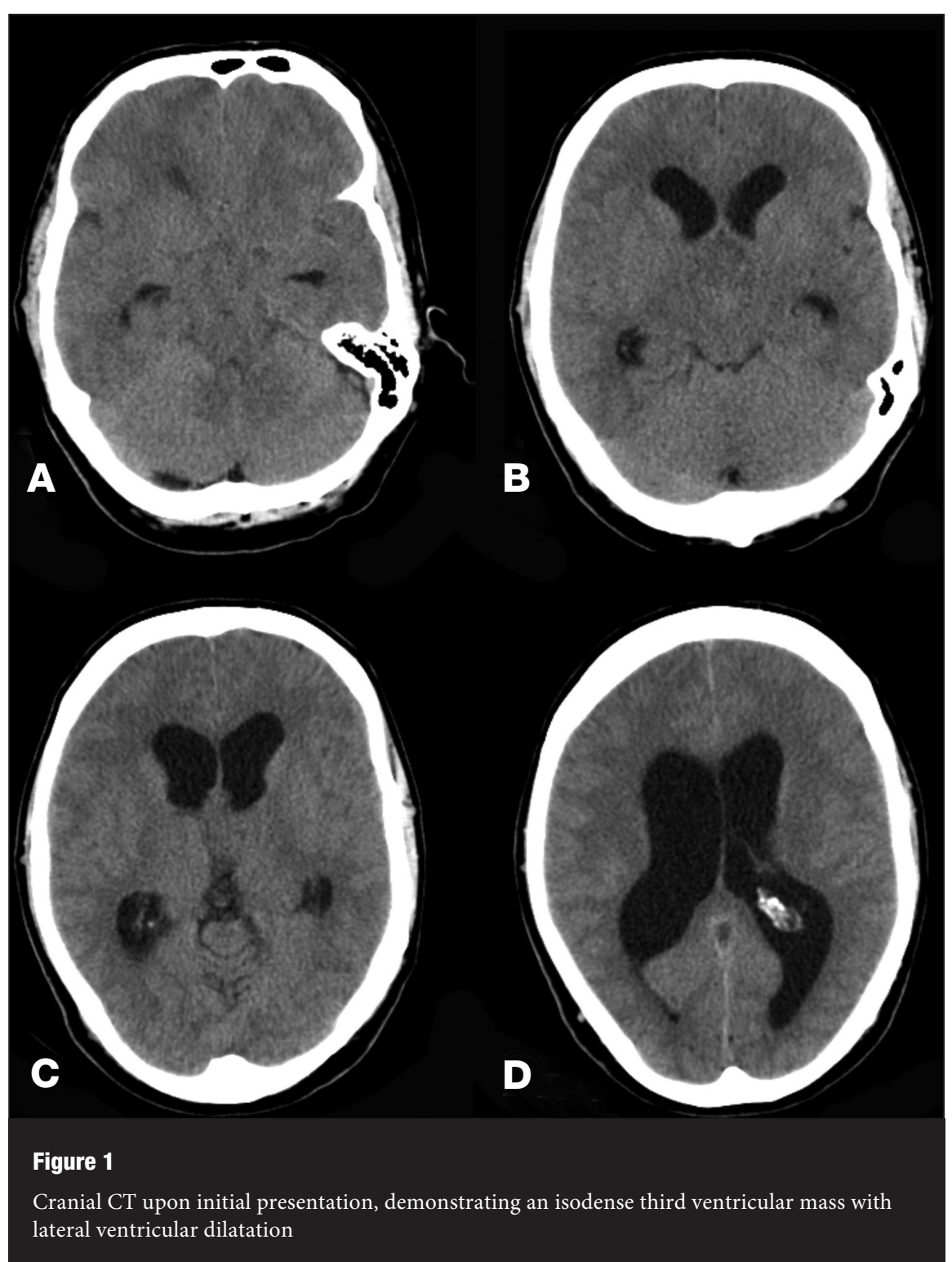

Abstract

The use of radiation treatment (RT) is usully reserved for residual or recurrent craniopha-
ryngiomas, and the role of RT alone and not as an adjunctive therapy to surgery has not been clearly defined. The authors describe a case of a 50-year-old man presenting with a large sion into the third ventricle, producing acute hydrocephalus. A ventriculoperitoneal shun was performed concurrently with an endoscopic biopsy. Treatment with fractionated stereotactic
radiosurgery (FSR) resulted in near resolution of radiosurgery (FSR) resulted in near resolution of
the lesion with no evidence of recurrence over six years. A review of RT for the treatment of craniopharyngiomas without surgical resectio

Introdion

Craniopharyngiomas are histologically benign extraaxial epithelial tumors that arise form embryologic remnants of Rathke's pouch. ${ }^{12}$
These rare lesions have an estimated incidence of 1.5 per million people per year, but comprise to their benign histology, craniopharyngiomas hypothalamus, optic apparatus, and endocrine system. Aggressive treatment is advocated, bu the optimal treatment is often debated.

Radical resection is often utilized as a first line
treatment due to the frequently large size of these lesions at presentation and associated mass effect. ${ }^{0,4}$ Such surgery, however, can carry endocrine dysfunction. ${ }^{26}$ For this reason, many favor subtotal resection with preservation of adjacent anatomical structures and adjuvant adiotherapy in isolation for the treatment of ngiomas is infrequent. Case Report

A 50-year-old man suffering from two months A emergency department with a dramatic deterio-
ration of his vision, limb paresis, and seizures. Cranial imaging demonstrated a $3.7 \times 2.5 \times 3.2$
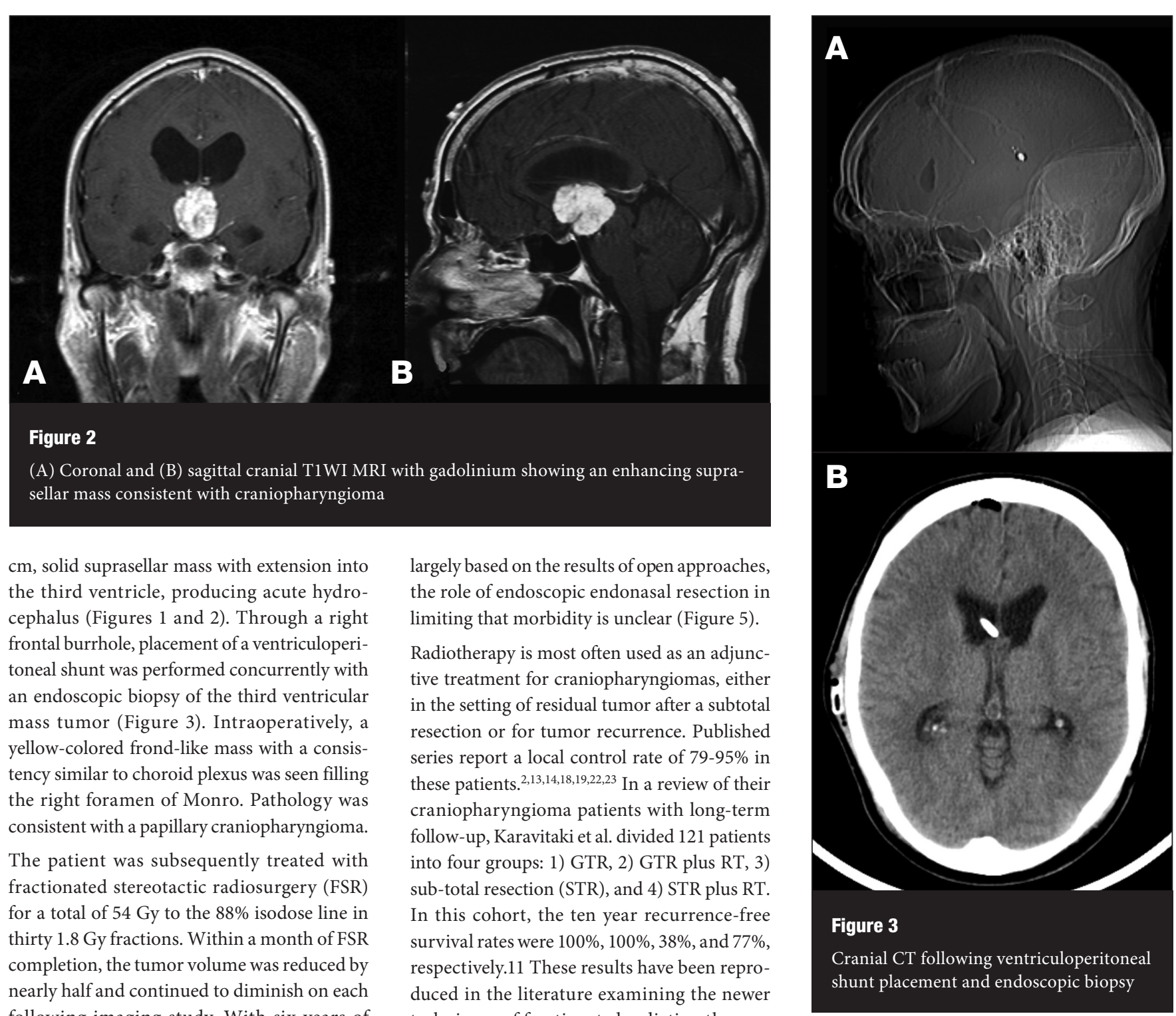

$\mathrm{cm}$, solid suprasellar mass with extension into the third ventricle, producing acute hydrocephalus (Figures 1 and 2). Through a right frontal burrhole, placement of a ventriculoperian endoscopic biopsy of the third ventricular mass tumor (Figure 3). Intraoperatively, a yellow-colored frond-like mass with a consistency similar to choroid plexus was seen filling the right foramen of Monro. Pathology was The patient was subsequently treated with fractionated stereotactic radiosurgery (FSR) thirty $1.8 \mathrm{~Gy}$ fractions. With completion the tumor volume was red bed nearly half and continued to diminish on each following imaging study. With six years of follow-up, the lesion continues to demonstrate near resolution with no recurrence and further
treatment has not been necessary (Figure 4). Discussion

The treatment of craniopharyngiomas is highly controversial. This controversy is further fueled by the myriad therapeutic modalities available cystic drainage, intracavitary chemotherapy, limited resection or gross total resection (GTR) and radiation therapy. The greatest debate exists between those favoring radical surgical excision lowed by adjuvant therapy is best to spare the potential morbidity associated with agressive surgery. While criticisms of surgical treatment are largely based on the results of open approaches, he role of endoscopic endo Radiotherapy is most often used as an adjunctive treatment for craniopharyngiomas, eithe in the setting of residual tumor after a subtotal resection or for tumor recurrence. Published series report a local control rate of 79-95\% in

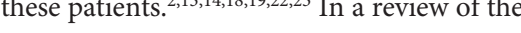
cronlow-up, Karavitaki et al divivided 121 patients into four grous 1) (TR, 2) GTR plus RT sub-total resection (STR), and 4) STR plus RT. In this cohort, the ten year recurrence-free survival rates were $100 \%, 100 \%, 38 \%$, and $77 \%$ respectively.11 These results have been reprotechniques of fractionated radiation therapy. Typically, 45-55 Gy in 1.8-2.0 Gy fractions are utilized and ten year local control rates for surgery with postoperative FSR are $57-8 \%$
compared to $31-42 \%$ with surgery alone.

The effect of radiotherapy for craniopharyng mas appears to be affected by the consistency of the lesion with more solid tumors having the ghest average control rate of $90 \%$. Tumors that $60 \%$ resp radiation effect is somewhat less clear. While some groups have not found a significant differnce between adamantinomatous and papillary nniopharyngiomas, Inoue et al. did find a better response in the latter. 410,15

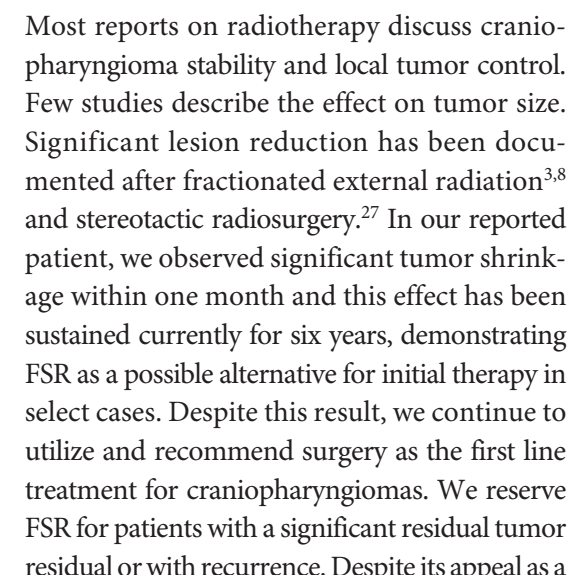

and local tumor control. re the efret on tun size. ed external radiation 3.8 r shrinkix native for initial therapy in residual or with recurrence. Despite its appeal as a 


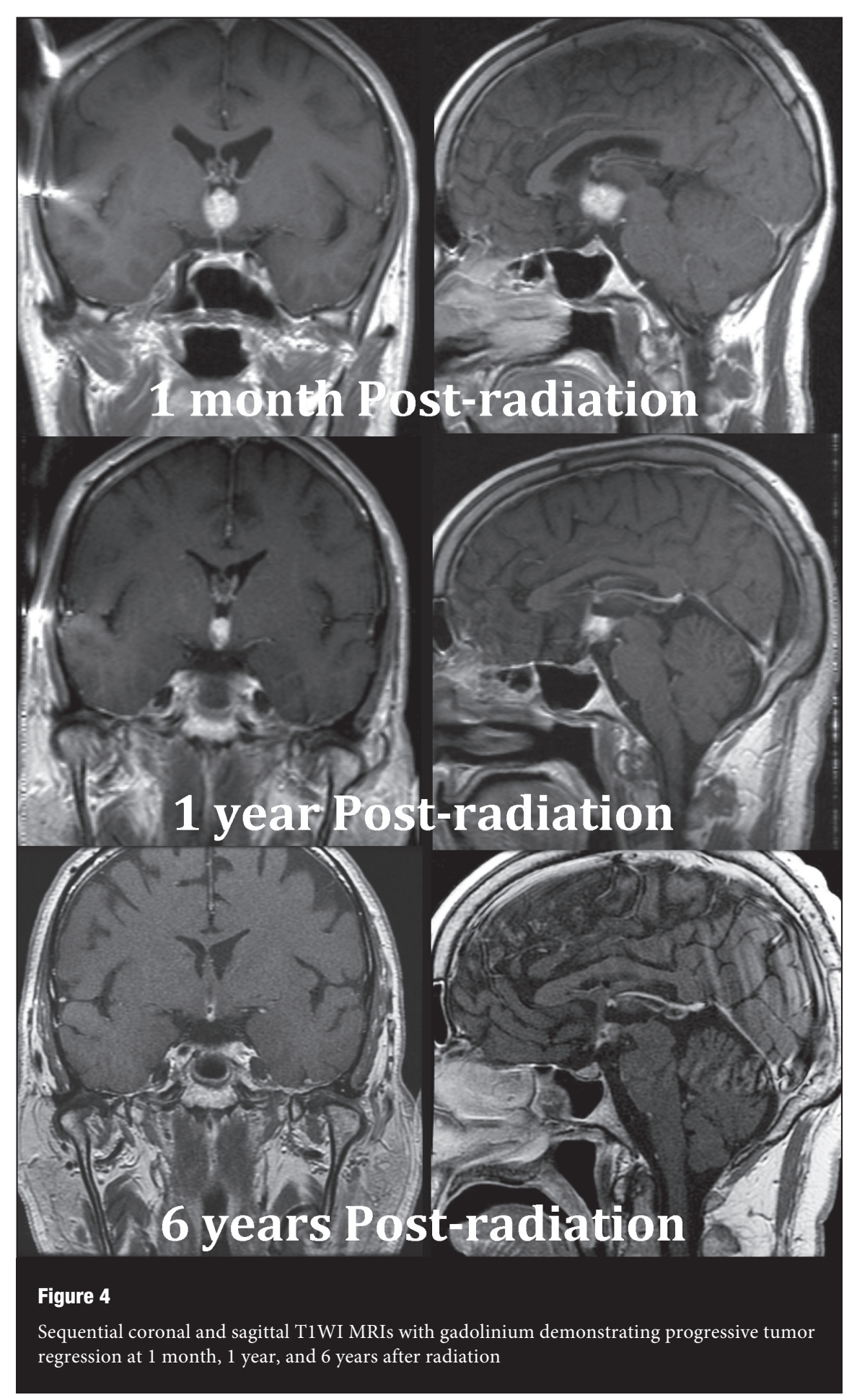

"less invasive" treatment, radiation is not a benign $\quad$ to the hypothalamic-pituitary-adrenal axis may in pediatric patients, neurocognitive impairment. phypogonadism, hypothalamic obesity and slep and optic neuropathy, $, 1,1,20$ Radiation effects
Conclusions

While surgery remains the initial treatment of chotween GTR versus STR gand emas, the debate endoscopic endonasal approaches continues to persist. Radiotherapy is often reserved for resida mas may be the most suitable for radiotherapyi surgical resection is not feasible.

References

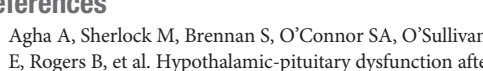

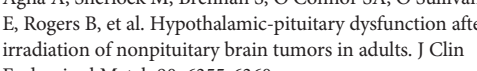

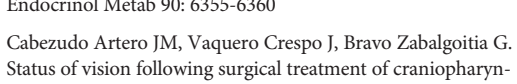

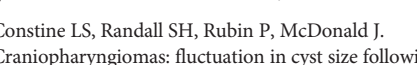
uurgery and radiation therapy. Neurosurgery $24: 53-9,919$

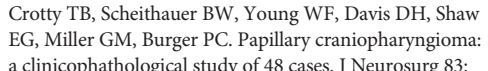
a clinicophathological study of 48 cases. . Neurosurg 83 .

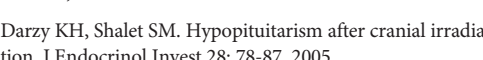

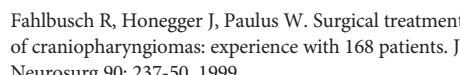

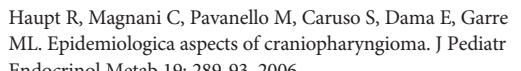

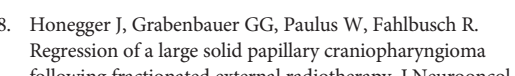

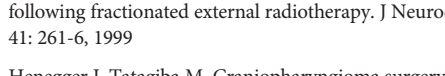

Henegger I T Tatagiba M. Cra
Pitutitary 11: 361-373, 2008

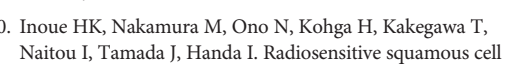

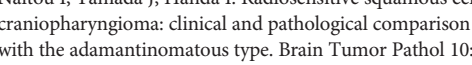
Karavitaki N, Bufuanic , Warner T, , etal

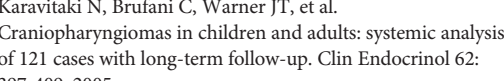
12. Karavitaki N, Cudlip S, Adams CB, Wass IA.
Carniopharyngiomas. Endocr Rev 27: $37-97,2006$

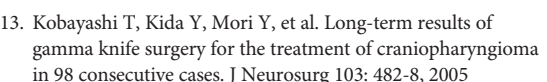
in 98 consecutive cases. $J$ Neurosurg 103: $482-8,2005$
14. Karavitakli N, Wass $\mathrm{AAH}$. Craniopharyngiomas. Endocrinol

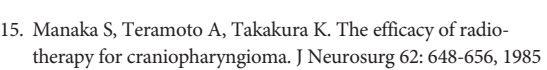
16. McCollough WM, Marcus RB Ir, Rhoton ALIJ, Ballinger

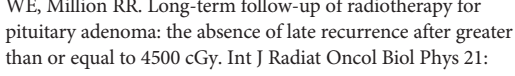

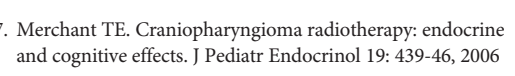

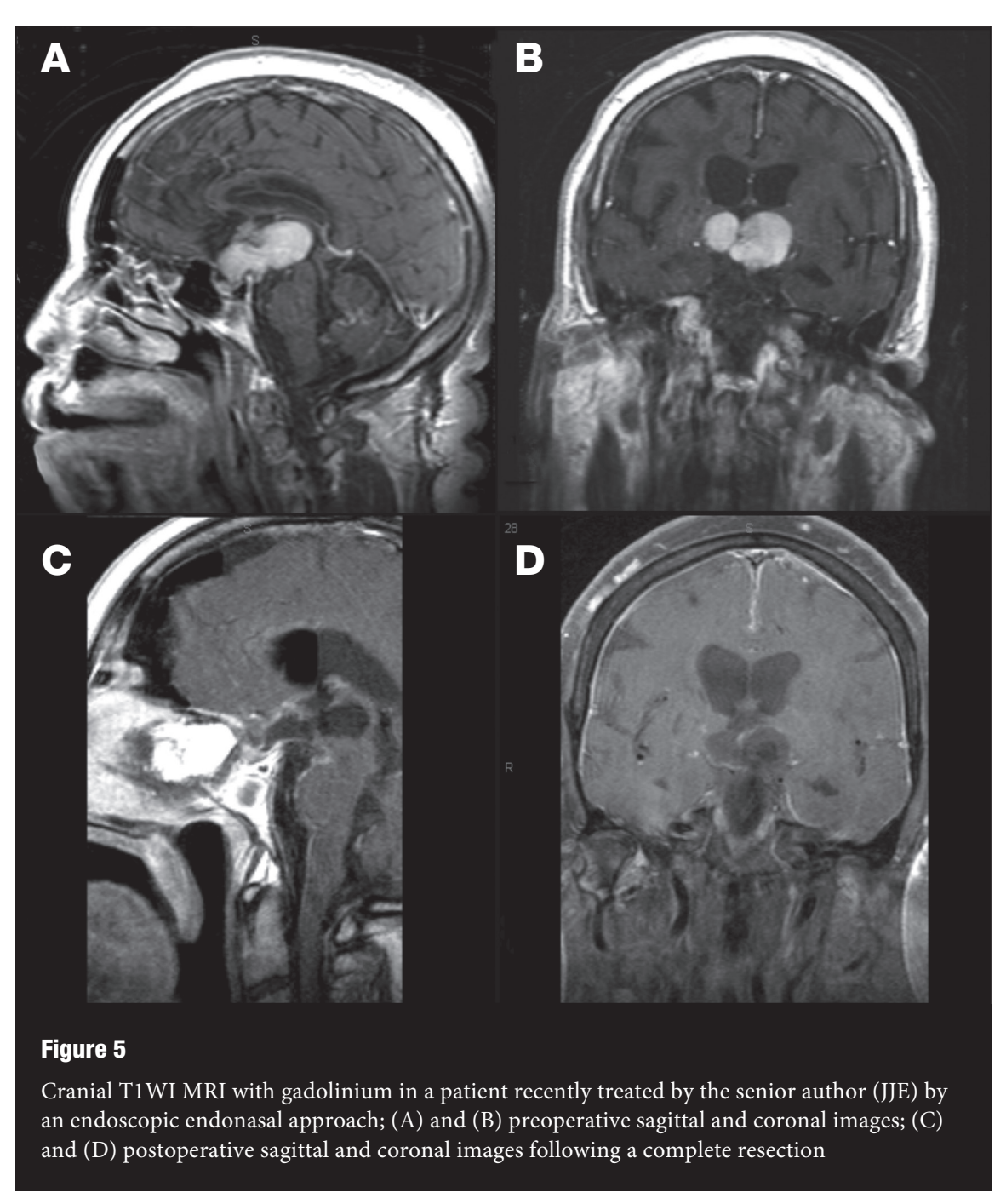

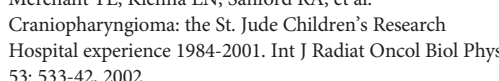

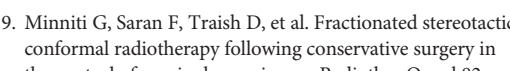
The control of franii
s. $0.5,2007$

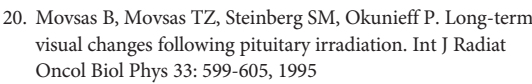

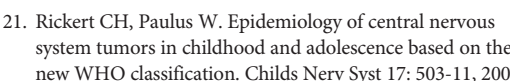

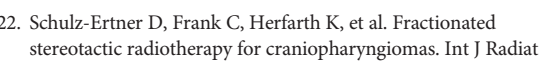

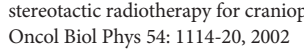

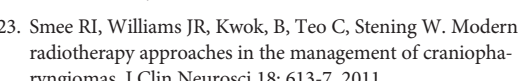

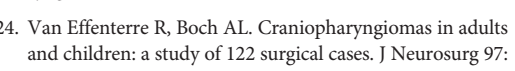

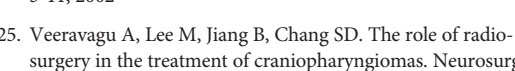

26. Yasargil MG, Curcic M, Kis M, Siegenthaler G, Teddy P, Roth (1)

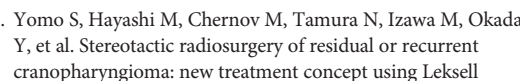

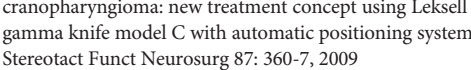

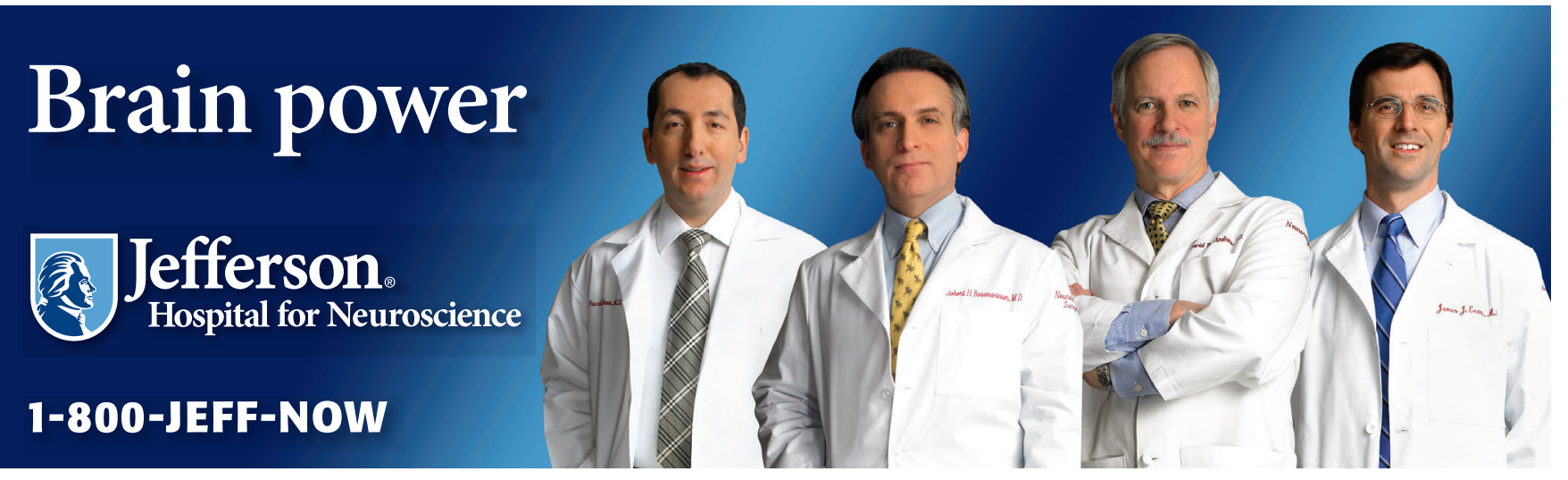

